\title{
Star Fruit Nephrotoxicity
}

\author{
Hasan $\mathrm{MJ}^{1}$
}

The country of fruits is Bangladesh. The climate and weather of Bangladesh are very suitable for fruit cultivation. At present there are about 130 varieties of fruits foundin the country. About 60 conventional and nonconventional fruits are cultivated in it ${ }^{1}$.

We all know that eating fruit on a regular basis can boost health and a vital source of essential vitamins and minerals and high in fiber. It also provides a wide range of healthboosting antioxidants. Taking fruits and vegetables can reduce a person's risk of developing various diseases. I am now going to discuss about unusual fruit that is

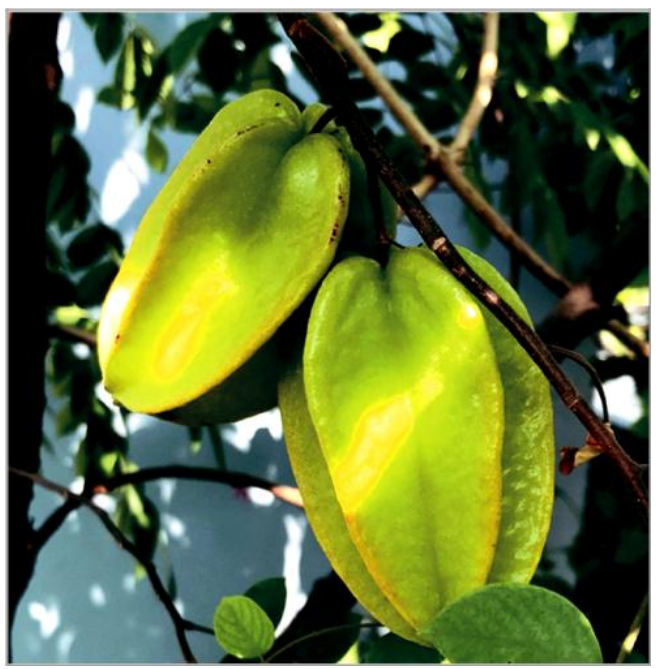

Starfruit or Carambola (Averrhoa Carambola) belongs to the oxalidacea family of fruits found in tropical regions, originally from Asia especially from Ceylon and Moluccas and is now a popular fruit in tropical and subtropical countries ${ }^{2}$.It is popular for its medicinal and nutritional values $^{3}$. Its hypoglycemic effects are considered to be beneficial in patients with diabetes mellitus, and it has been promoted as a traditional remedy for diabetes ${ }^{4}$.
But Starfruit intake can be fatal for patients with renal disease (CKD) because it contains a neurotoxin called caramboxin ${ }^{5}$. In patients without nephropathy, the neurotoxin (carambola) is absorbed, distributed and excreted by the kidney, without compromising the body. In CKD patients, the neurotoxin is not properly excreted resulting its serum levels are elevated, which would allow its passage through the blood-brain barrier and consequent action on the Central Nervous System (CNS) $)^{5-7}$.

In these patients, star fruit may cause mild to severe neurotoxicity including

- Hiccups,

- Vomiting,

- Asthenia,

- Mental confusion,

- Seizures,

- Coma and death ${ }^{8-10}$.

Star fruit is a rich source of oxalates. In one study, Chen et al. measured $202 \mathrm{mg} / \mathrm{dl}$ of oxalic acid in fresh sweet juice and 829 $\mathrm{mg} / \mathrm{dl}$ of oxalic acid in fresh sour juice. In comparison with homemade and medicinal preparations of pure sour star fruit juice often have high concentrations of oxalate. After consuming the fruit juice, oxalates complex with intra-luminal calcium and magnesium to form insoluble complexes in the gastro intestinal tract, which prevent them from getting absorbed ${ }^{11}$. When it is consumed in large amounts, especially in empty stomach, increased level of free oxalates remain available for absorption into the circulation. These free oxalates are

1 Dr. Mahmud Javed Hasan

Associate professor and Head

Department of Nephrology

Community Based Medical College Bangladesh

Address of correspondence:

Email :dr.porag@gmail.com

Mobile : 01712177065 
filtered through the kidneys where they precipitate into calcium oxalate crystals and mediate renal damage by tubular obstruction. Some studies have shown a high serum oxalate level to be associated with increased apoptosis of renal epithelial cells which contributes to nephrotoxicity ${ }^{12}$.

Some studies show that, many patients with star fruit toxicity present within hours of ingestion with gastrointestinal symptoms (vomiting and abdominal pain). These are suspected to be due to direct corrosive effects of dietary oxalates rather than systemic effects ${ }^{13}$. This may be followed by a reduction in urine output in patients who develop acute kidney injury (AKI).

A case study was conducted in Bangladesh by MA Azim and A Salam in 2015 confirming that, a fasting individuals developing nephropathy after having $300 \mathrm{ml}$ of pure star fruit juice ${ }^{19}$.

Star fruit toxin's effects on Kidney

- Acute kidney injury from acute oxalate nephropathy and acute tubular necrosis.

- Renal stone disease.

- Deterioration of renal function in patients of Chronic kidney disease ${ }^{14}$

There is no specific treatment for star fruit induced acute kidney injury. The mortality rate after star fruit intoxication is as high as $20 \%-40 \%$ despite treatment with hemodialysis (HD) or supportive care ${ }^{15}$. Early and aggressive HD can be lifesaving in uremic patient with star fruit intoxication; however, it is not always effective. It is also reported that hemoperfusion (HP) is beneficial in improving neurological dysfunction in dialysis patients with star fruit intoxication. Some case report describes a patient with severe CKD not yet on dialysis, manifested coma and status epilepticus because of star fruit intoxication. Despite rapid treatment with $\mathrm{HP}$ and $\mathrm{HD}$, the patient died. Because of this case, it is recommended that all CKD patients be warned to avoid star fruit ${ }^{16}$. Many nephrologists use steroids for the management of acute oxalate nephropathy. Recently the effect of $\mathrm{N}$ - acetyl cysteine (NAC) on star fruit induced acute kidney injury was studied in animal models. The results suggest that NAC may attenuate renal dysfunction by reducing oxidative stress, oxaluria and inflammation ${ }^{17}$.

Nephrotoxicity of Starfruit must be considered in any person who is in the developing phase of unexplained acute kidney injury. The history is the essential key to reach a diagnosis early. It is important to prevent star fruit nephrotoxicity by educating the public and especially diabetics to avoid consuming star fruit, especially in fasting or dehydrated state. Further studies need to be done to identify the dose and type of star fruit, which could lead to nephrotoxicity. In the interim the use of star fruit, specifically as a therapy to achieve better glycaemic control in diabetes, should be discouraged ${ }^{17}$.

In country like Bangladesh where star fruit consumed routinely, it is vital to increase awareness among patients and doctors about the risks of its consumption. Patients with renal disease, those at risk of developing it, or those undergoing procedures such as HD are the target population for these recommendations. People with normal renal function should also avoid or at least limit the intake of star fruit since they may also be affected ${ }^{18}$.

\section{References:}

1. www.ais.gov.bd

2. Morton JF. Fruits of warm climates. Miami: Flair Books. 1987.p.125-8.

3. Muthu N, Lee SY, Phua KK, Bhore SJ. Nutritional, medicinal and toxicological attributes of star-fruits (Averrhoa Carambola L.): a review. Bioinformation.2016;12:420-4.

4. Gunasekara LCA, Fernando PHP, Sivakanesan R. A Preliminary Study on the Hypoglycaemic Effect of Averrhoa carambola (Star Fruit) in Rats, vol. 16. Sri Lanka: Proceedings of the Peradeniya University Research Sessions;2011. p. 83.

5. Martin LC, Caramori JST, Barretti $P$, Soares VA. Soluço intratável desencadeado por 
ingestão de carambola ("Averrhoa carambola") em portadores de insuficiência renal crônica. J Bras Nefrol.1993;15:92

6. Cuppari L, Avesanni CM, Kamimura MA. Nutrição na doença renal crônica. Barueri: Manole; 2013.

7. Moysés Neto M. Star fruit as a cause of acute kidney injury: a case report. J Bras Nefrol.2014;36:118-20.

8. Neto MM, Robl F, Netto JC. Intoxication by star fruit (Averrhoa carambola) in six dialysis patients? (Preliminary report). Nephrol Dial Transplant.1998; 13: 570-572.

9. Chang JM, Hwang SJ, Kuo HT et al. Fatal outcome after ingestion of star fruit (Averrhoa carambola) in uremic patients. Am J Kidney Dis.2000; 35: 189-193.

10. Neto MM, Da Costa JA, Garcia-Cairasco $N$ et al. Intoxication by star fruit (Averrhoa carambola) in 32 uraemic patients: treatment and outcome. Nephrol Dial Transplant.2003; 18: $120-125$.

11. Chen CL, Fang HC, Chou KJ, Wang JS, Chung HM. Acute oxalate nephropathy after ingestion of star fruit. Am J Kidney Dis. 2001;37:418-22.

12. Fang HC, Lee $P T$, Lu PJ, Chen CL, Chang TY, Hsu CY, Chung HM, Chou KJ. Mechanisms of star fruit-induced acute renal failure. Food Chem Toxicol. 2008;46:174452.

13. Konta T, Yamaoka M, Tanida H, Matsunaga $T$, Tomoike $H$. Acute renal failure due to oxalate ingestion. Intern Med.1998;37:762-5.

14. Mahmood N. Review article: Star Fruit Intoxication. AKMMC J. 2015; 6(2): 30-33.

15. Chang JM, Hwang SJ, Kuo HT, et al. Fatal outcome after ingestion of star fruit (Averrhoa carambola) in uremic patients. Am J Kidney Dis.2000;35:189-193.

16. Tsai Jen Pi, Fang Te Chao, Wang ChihHsien, Chung Tien-Hua, Hsu Bang Gee. Case Report: Fatal Outcome After Ingestion of Star Fruit in a Severe Chronic Kidney Disease Patient. Dialysis \& Transplantation. March 2009.
17. Wijayaratne et al. Star fruit nephrotoxicity: a case series and literature review. BMC Nephrology.2018. 19:288

18. Aranguren $C$, Vergara $C$, Rosselli $D$. Review Article: Toxicity of Star Fruit (Averrhoa carambola) in Renal Patients: A Systematic Review of the Literature. Saudi J Kidney Dis Transpl.2017;28(4):709-715.

19. Azim MA, Salam A. Case Study: Star fruit intoxication leading to acute kidney injury. Bang Med J Khulna. 2015; 48 : 37-39. 